\title{
Assessing the Higher Education Settings after the Transition to Online Learning: Exploring Teaching, Assessments, and Students' Academic Success
}

\author{
Nahla Moussa* \\ American University in the Emirates, Dubai, UAE \\ https://orcid.org/0000-0003-1342-8201
}

\begin{abstract}
This empirical research report intended to explore the impact of the sudden transition to online learning and teaching and assessment at higher education institutions in the United Arab Emirates (UAE). Furthermore, the study assessed the difference in students' academic achievement and their perception of the transition to online learning. A mixed-method research design was adopted to achieve the purpose of this research paper. Content analysis, the Correlation Coefficient, and Simple Linear Regression were supportive analysis tools. Data analysis proved that the higher education system in the UAE embraced appropriate teaching and assessment approaches to the online mode of teaching and learning. Moreover, higher education students maintained high academic success after transitioning to online learning. Students' perception of the transition to online learning positively correlated to students' academic success. Thus, higher education students maintained a decent level of academic success after transitioning to the online mode of learning.
\end{abstract}

Keywords: teaching approaches; assessment; academic success; online learning; higher education

\section{Introduction}

Higher education is a critical stage that is worthy of focus and study. Higher education refers to any post secondary educational setting that provides a dynamic environment for teaching and learning in all fields of knowledge where students are enrolled to earn an academic degree. Many educators focused heavily on pedagogies at the college level (McMinn et al., 2020; Sandri, 2020). Recently, higher education has experienced a dramatic transition and expansion in many countries around the globe. Many components such as teaching approaches, assessment tools, and students' academic success could reflect the

*Corresponding author: Nahla Moussa, nahla.moussa@aue.ae 
quality of learning and learners. Analyzing the higher education system entails focusing on these components. Many research studies (e.g., Chaturvedi et al., 2021; George, 2020; O'Brien \& Blue, 2018) discussed and focused on teaching approaches, assessment strategies, and academic success in higher education from different perspectives, and the results differ based on the study perspective.

The past decades witnessed a rapid growth in tertiary education in the Middle East. The United Arab Emirates (UAE) is a fast-growing Middle Eastern country located in the Gulf area. The UAE Ministry of Education (MoE) continuously puts forth the effort to enhance higher institutions' productivity, strengthen scientific inquiry, and aims to graduate human cadres ready to face the challenges of this rapidly developed future and achieve development in all fields. The UAE Ministry of Education embraces a well-structured context, supported with an effective global criterion to inspire learners from all grade levels. The country aims to encourage students' competencies and abilities throughout their education journey to facilitate lifelong learning and prepare them to face the changes of the dynamic future (Ministry of Education [MoE], 2019).

In alignment with achieving the strategic goals of the UAE's Ministry of Education, the current research study is aiming at exploring the quality of teaching and learning depending on two dimensions; (1) exploring the change in teaching and assessment during the unexpected transition to online learning, and (2) measuring students' perception of the sudden transition to online learning and the change in their academic success pre and post the transition. Thus, the findings will provide a clear picture of teaching and assessment models that have been implemented during online learning. On the global level, the study summarizes the educational context implemented in higher education settings in the UAE as a multicultural country that hosts a diverse group of residents from across the globe. The findings of this study could help students who aim to study abroad in the exchange programs in the UAE. Furthermore, other universities can benefit from the findings in many ways to improve their practices.

\section{The Research Problem}

Early at the beginning of 2020, the acute influence of COVID surprised the world-19 Pandemic, which urged applying safety measures to limit the prevalence and the impact of the COVID - 19. One of the safety measures is the transition of work and education to online operation, which interrupted the education system across all grade levels and affected work performance and academic success. Yang and Ma (2020) revealed that people's emotions and subjective well-being deteriorate by $74 \%$, which could influence people's performance. The recent research of Daniels (2021) and a group of researchers discovered that students' perception of success, engagement in a learning experience, and objectives achievement had significantly deteriorated; simultaneously, there is a wave of widespread normalization of cheating (Daniel et al., 2021). Furthermore, the transition to online learning is challenging for 
higher education settings, and there is a need for implementing new curriculum and teaching approaches to suit the online learning demands (Toquero, 2020). Thus, the mentioned factors and the transition to online teaching and learning may impact the education system negatively. The research on assessing higher education and academic success after the sudden transition to online learning in the Middle East is insufficient; as a result, there is a need for further investigation.

\section{Literature Review}

\subsection{Teaching, Learning, and Assessment in the UAE}

The view of teaching at the higher education level has shifted radically from a traditional way of content delivery to embracing active learning strategies in teaching and learning. Traditional teaching strategies focus on transferring subject content to students instead of considering their learning styles and consistent teaching strategies. Pozo Sanchez et al. (2019) revealed that active learning is more applicable than traditional learning techniques. According to Park and Choi (2014), active learning classroom strategies inspire students and motivate them towards learning more than traditional classrooms do. Furthermore, students' learning is influenced by instructors' quality and pedagogies (Canales \& Maldonado, 2018). Active learning strategies focus on engaging students in learning activities and providing them opportunities to perceive the content effectively. The UAE puts forth efforts to develop the higher education sector. As the UAE is a fast-growing country, higher education embraces advanced technology in teaching and learning (Al-Qirim, 2016). According to the UAE Vision 2021, 2030, Knowledge-Economy Initiative is added as a key performance to achieve the Vision, which facilitates the UAE's progress towards pioneering world knowledge economy by approaching 2030 (UAE Strategic Report 2021, 2010).

It was revealed that the education was Islamic constructed and oriented as social constructivist, which was based on critical thinking ability and questioning regarding the content (Jackson, 2015). The increasing attempts of the UAE to bring its education to a world-class and advanced level push it to adopt the updated teaching approaches and shift to the student-centered approach to facilitate the learning process. The student-centered approach depends on thinking actively during the teachings. The recent research study of McMinn et al. 2020 uncovered that instructors in higher education institutions in UAE adopt a student-focused approach effectively in teaching and delivering the content; however, some instructors and faculty use a combination of a student-focused approach and a teacher-focused approach. Moreover, the study of Al-Naqbi and Alshannag (2018) showed that the higher education students have a high level of awareness with positive attitudes toward sustainability in education, which emphasizes embracing an advanced education system. This era has been recognized with the identification of skillful individuals as the base for economic growth and social welfare in the 21st century. In this perspective, the higher education sector designates a vital component in developing human capacities and innovation and plays an essential role in the knowledge economy's prosperity and sustainability (Al-Naqbi \& Alshannag, 2018). 


\subsection{Transition to Online Learning}

The consequences of the COVID-19 have disrupted the education system across the globe, which necessitated surpassing preparation to find an urgent address to that issue. In no time, the education systems entirely across all grade levels, including higher education, mandated a total transformation to implement remote teaching and learning (Mishra et al., 2020). As the education system is transformed into a virtual learning mode, some challenges are expected to be faced. As revealed by Carolan et al. (2020), the sudden transition to online learning came with new expectations and demands from both instructors and students, such as rapid adaptation to e-learning platforms. As a result, an immediate need for curriculum and instructional design modification to align with the online learning environment has emerged (Dwivedi et al., 2020).

Like many other countries, higher institutions in the UAE responded to the shutdown of COVID - 19 Pandemic by transitioning to an online mode of teaching and learning. As stated by Nathan (2020), the online learning experience uncovered some challenges that need to be addressed to provide an effective online learning environment. Transitioning to online learning has its consequences and requirements, including a comprehensive readiness of the universities, faculty members, curriculum, pedagogies, and assessment. Nathan (2020) conducted an informal survey to investigate higher education leaders' perceptions of the transition to online learning in the UAE. The findings revealed that many leaders viewed the online learning experience positively and showed effective results than the expectation.

\subsection{Perception of Academic Success}

Success or academic achievement is a broad concept that incorporates various meanings. Investigating the meaning and perception of academic success revealed several perceptions of academic success. Some researchers and educators identify academic success by evaluating students' grades; however, students view success as learning through gaining knowledge and skills (Cachia et al., 2018). One of the definitions of students' academic success is the concept of personal and academic achievement, which describes students' engagement in meaningful learning activities to acquire preferred knowledge and skills that promote accomplishing academic goals. According to White (2015), academic success can be described as students' endeavors towards obtaining an academic degree associated with their area of specialization or concentration, averting no academic weakening or failure; the view of success differs among students. Success has been investigated by researchers such as York (2015) and a group of colleagues, and their research findings revealed six mechanisms of grounded definition to explain academic success to include: satisfaction, academic achievement, skills and competencies procurement, persistence, accomplishing learning objectives, and career success (York et al., 2015). In the context of achievement, academic success can be considered an indicator of students' capacities, including their gained skills and abilities. In some educational settings, the concept of academic success is associated with obtaining high marks in the course assessment. 
Nonetheless, Hepworth et al. (2018) discovered significant predictors of students' success, such as academic preparedness, social integration, and perceived institutional commitment to student success. Mihaela (2015) suggested that psychological factors play a great role in intellectual ability. Besides, faculty and instructors need to understand the components of students' success to help them increase their success (Jaquette \& Curs, 2015). This research paper views academic success as attaining desired learning outcomes assessed by students with Cumulative Grade Point Average (CGPA).

\section{Methods and Study Design}

A mixed-method design was implemented to help readers understand any inconsistencies between quantitative results and qualitative findings and allow instructors and professors to generously explain how their teaching and assessment have been changed radically because of the transition to online learning.

\subsection{Research Questions}

Two types of questions are proposed to achieve the study objectives.

\section{The Qualitative/Interview Questions:}

1. How instructors have adapted their teaching approaches after transitioning to online learning in higher education settings?

2. How instructors have adapted their assessment approaches after transitioning to online learning in higher education settings?

\section{The Quantitative Questions:}

1. How students' GPAs have been changed after transitioning to online learning in higher education settings?

2. What is the students' perception of the sudden transitioning to online learning?

3. What is the relationship between students' GPA and the perception of the transition to online learning?

\subsection{Data Collection}

Two stages were implemented to collect data (1) qualitatively: semi-structured interviews with higher education professors and instructors were conducted. The interviewees were contacted via emails. The invitation was sent to more than 30 educators; a total of 22 educators from the largest higher institutions in the UAE accepted the invitation. The interviews were conducted individually and virtually via the Zoom video communication technology and continued for 1 hour each. Interviewees were asked about the teaching strategies and assessment pre and post the transition. All interviews were recorded and saved for content analysis. Data was coded/described in categories to form a general response/theme. (2) Quantitatively: a Likert scale survey was distributed to students in which Liaw's model (2008) was adopted to evaluate students' perception of the transition. The questionnaire was designed on Google forms, including the demographic survey, which requires providing the students' CGPA 1 (pre the transition) and CGPA 2 (post the transition). The consent form was attached to the survey, in addition to the procedure for responding to questions. The researcher invited students to attend a virtual session and 
respond to the questionnaire. SPSS 22.0 was used for data analysis and conclusion.

\subsection{Instrumentation}

For this study, students' CGPA 1 \& 2 was the indicator of the difference in students' academic success. To determine the students' perception of the transition to online learning, Liaw's model (2008) was employed. Although Liaw's model (2008) comprehends eight domains, all measure students' perception towards e-learning from variable perspectives, and for this research study, only three domains are the most relevant to achieve the study objectives. The three domains were adopted to measure students' perception of the transition to online learning including, Perceived satisfaction (4 questions), Perceived usefulness (3 questions), E-learning effectiveness (3 questions). Liaw's model as Likert scale consisted of 7 points varied from $1=$ strongly disagree to $7=$ strongly agree. Calculating the total score of each domain can be achieved by finding the mean score of each domain. Based on that scale, positive perception was determined by a total score higher than 4 .

\subsection{Instrument Reliability and Validity}

According to Liaw (2008), the model has a high internal consistency, indicated by Cronbach's a $=0.97$ for the model entirely, and items' coefficients ranged from 0.57 to 0.80 , indicating sufficient reliability of the scales. For the current study, Cronbach's a was calculated, ranging from .735 to .822 for three domains indicating satisfactory reliability (See Table 1). For the instrument validity, the scale has been tested over time by many researchers, showing high validity. In addition, it was sent to a panel of experts in the measurement in the UAE to ensure its validity for the higher education students in the UAE. Questions were carefully reviewed, and the final version was distributed to the respondents.

Table 1: Internal consistency of the perception of the transition to online learning

\begin{tabular}{|l|l|l|}
\hline Domain & Cronbach's Alpha & No of Items \\
\hline Perceived satisfaction & .822 & 4 \\
\hline Perceived usefulness & .808 & 3 \\
\hline $\begin{array}{l}\text { E-learning } \\
\text { effectiveness }\end{array}$ & .735 & 3 \\
\hline
\end{tabular}

\subsection{Sample Demographics}

This research study combined two groups of participants (1) educators' group: 22 educators aged 35 to 48 years. Academically, from a master's degree to a Ph.D., their academic rank ranged from instructor to associate professor with more than seven years of teaching experience in higher education settings, and they have a current teaching role in either federal or private institutions.(2) Students' group: a total of 598 respondents were distributed as follows; male students and female students were 257 (43\%) and 341 (57\%), respectively. Students were enrolled in federal or private institutions and represent different colleges (See Table 2 \& Figure 1). Students were allowed to participate in the study only if they were in the second year (sophomore) to provide their CGPA pre and post transition; sample educational level is shown in table 3. The sample 
came from a diverse group of students (See Table 4). Descriptive analysis showed that the sample's age varies between 18 to 39 and averaged 22.186, with a median of 21 and a mode of $20, S D=3.8451$.

Table 2: Distribution and percentages of participants by institution

\begin{tabular}{|l|l|l|l|l|l|}
\hline \multicolumn{2}{|c|}{} & Frequency & Percent & $\begin{array}{l}\text { Valid } \\
\text { Percent }\end{array}$ & $\begin{array}{l}\text { Cumulative } \\
\text { Percent }\end{array}$ \\
\hline \multirow{4}{*}{ Valid } & American University in the Emirates & 170 & 28.4 & 28.4 & 28.4 \\
\cline { 2 - 6 } & American University of Sharjah & 144 & 24.1 & 24.1 & 52.5 \\
\cline { 2 - 6 } & University of Sharjah & 95 & 15.9 & 15.9 & 68.4 \\
\cline { 2 - 6 } & Higher Colleges of Technologies & 59 & 9.9 & 9.9 & 78.3 \\
\cline { 2 - 6 } & Ajman University & 27 & 4.5 & 4.5 & 82.8 \\
\cline { 2 - 6 } & United Arab Emirates University & 56 & 9.4 & 9.4 & 92.1 \\
\cline { 2 - 6 } & American University in Dubai & 29 & 4.8 & 4.8 & 97.0 \\
\cline { 2 - 6 } & Others & 18 & 3.0 & 3.0 & 100.0 \\
\cline { 2 - 6 } & Total & 598 & 100.0 & 100.0 & \\
\hline
\end{tabular}

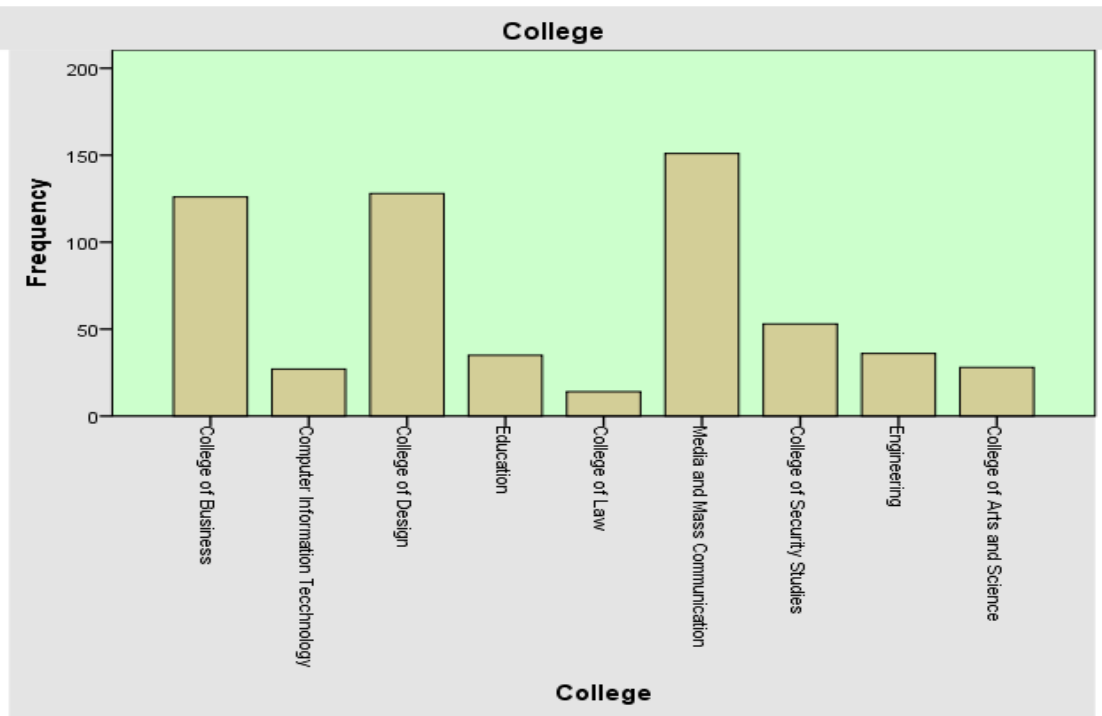

Figure 1: Sample distribution by college

Table 3: Sample distribution by education level

\begin{tabular}{|l|l|l|l|l|l|}
\hline \multicolumn{2}{|c|}{} & Frequency & Percent & $\begin{array}{l}\text { Valid } \\
\text { Percent }\end{array}$ & $\begin{array}{l}\text { Cumulative } \\
\text { Percent }\end{array}$ \\
\hline \multirow{7}{*}{ Valid } & $\begin{array}{l}\text { Undergraduate Sophomore } \\
\text { (second year) }\end{array}$ & 240 & 40.1 & 40.1 & 40.1 \\
\cline { 2 - 7 } & Undergraduate Junior (third year) & 226 & 37.8 & 37.8 & 77.9 \\
\cline { 2 - 7 } & $\begin{array}{l}\text { Undergraduate Senior (fourth } \\
\text { year) }\end{array}$ & 132 & 22.1 & 22.1 & 100.0 \\
\cline { 2 - 7 } & Total & 598 & 100.0 & 100.0 & \\
\hline
\end{tabular}


Table 4: Sample distribution by nationality

\begin{tabular}{|l|l|l|l|l|l|}
\hline \multicolumn{2}{|c|}{} & Frequency & Percent & Valid Percent & Cumulative Percent \\
\hline Valid & UAE & 188 & 31.4 & 31.4 & 31.4 \\
\cline { 2 - 6 } & Egypt & 64 & 10.7 & 10.7 & 42.1 \\
\cline { 2 - 6 } & Lebanon & 16 & 2.7 & 2.7 & 44.8 \\
\cline { 2 - 6 } & Syria & 50 & 8.4 & 8.4 & 53.2 \\
\cline { 2 - 6 } & Palestine & 61 & 10.2 & 10.2 & 63.4 \\
\cline { 2 - 6 } & Jordan & 36 & 6.0 & 6.0 & 69.4 \\
\cline { 2 - 6 } & Yemen & 19 & 3.2 & 3.2 & 72.6 \\
\cline { 2 - 6 } & KSA & 16 & 2.7 & 2.7 & 75.3 \\
\cline { 2 - 6 } & Iraq & 13 & 2.2 & 2.2 & 77.4 \\
\cline { 2 - 6 } & Algeria & 11 & 1.8 & 1.8 & 79.3 \\
\cline { 2 - 6 } & USA & 12 & 2.0 & 2.0 & 81.3 \\
\cline { 2 - 6 } & India & 11 & 1.8 & 1.8 & 83.1 \\
\cline { 2 - 6 } & Pakistan & 24 & 4.0 & 4.0 & 87.1 \\
\cline { 2 - 4 } & Sudan & 11 & 1.8 & 1.8 & 89.0 \\
\cline { 2 - 5 } & Iran & 43 & 7.2 & 7.2 & 96.2 \\
\cline { 2 - 6 } & Other & 23 & 3.8 & 3.8 & 100.0 \\
\cline { 2 - 5 } & Total & 598 & 100.0 & 100.0 & \\
\hline
\end{tabular}

\section{Data Analysis and Results}

\subsection{Qualitative Data Findings}

Content analyses were utilized to generate data from semi-structured interviews with 22 college professors and instructors. Two themes were presented to answer the first research question.

\subsubsection{Teaching Adaptation}

Data analysis revealed that traditional teaching techniques were common approaches that were adopted by both federal and private higher education institutions in the UAE. However, the practices differ among institutions and instructors. Since the accreditation authority is the same for all institutions; as a result, all institutions follow the same criteria released by the accreditation authority. According to content analysis, most respondents used to implement the traditional teaching techniques, including preparing the lesson heavily depending on the main textbook enriched with additional resources such as published articles or other reliable resources. Most of the class activities were implemented in printed papers. As stated by respondents, the teaching process started with a general introduction to the topic, oral discussion implemented by "think - pair - share" activity, and then "mind mapping" represented by written activity.

Moreover, technology-based learning was limited to video analysis for most of the interviewees, except for three out of 22, who stated that they sometimes flipped their classroom; however, that was not applicable to all courses; it depends on the course nature. The teaching material was constrained to a visual presentation by Microsoft PowerPoint PPT. Instructors used to post the material on the students' university portal a few days before the class time. No recorded sessions were available. 
As stated by some respondents, "Before the transition to online learning, the lack of recorded sessions influences the learning process, if a student is not attending, the class activities and group discussion will be missed, a main part of learning will be missed, which creates a gap, when a student comes back, it is difficult to fill in that gap."

Before the transition, all office hours, meetings, the extra-curricular activity includes a guest speaker, field trips, peer lectures, and forums, were conducted physically and used to enhance the social communication skills and learning outcomes.

As content analysis revealed, professors and students were unprepared for that sudden movement. Nonetheless, the continuous professional development activities helped them to quickly adapt to appropriate strategies and enhance their online teaching capacities.

As mentioned by two respondents, "I was surprised by the sudden transition that was decided in no time, how and when I will practice it? how can I succeed in an online classroom like I was in my traditional classroom". Respondents continued, "I need enough time to practice and impress my students with my performance in the virtual classroom." "Now, I need to transfer my teaching experience into e-teaching experience. How long does it take me to build a solid e-experience?".

The content analysis demonstrated that implementing online learning followed the exact outlines of face-to-face teaching but with different practices. All higher education institutions in the UAE transferred directly to synchronous online learning where instructors meet students at the same time of the session. Moreover, the sessions were recorded and saved in the repository for students' reference. Participants stated that "to align with the transition demands, each institution chose its platform to facilitate online learning and conveying the content." The difference between federal and private institutions lies in the choice of Learning Management System (LMS). The federal universities have their own LMS, which were employed, whereas private institutions integrated additional communication technologies such as Zoom, MS Teams, and Moodle.

Based on the provided data, instructors need to alter their teaching and learning activities to e-activities. The online teaching process starts with accessing the meeting channel virtually, where the instructor and students can see and hear each other. The instructor can share his/her screen to reflect the teaching material. However, the PPT was shared with students in the virtual session, but instructors found it insufficient to keep students engaged and focused; as a result, most of the respondents (16 out of 22 ) stated that they needed to be more creative in online teaching, learning activities and classroom management. As revealed by respondents, the traditional teaching methods were not helpful. Hence, instructors need to develop many professional skills to meet the online learning demands. Technology-based learning has been mandated and should be developed. Some respondents stated that they enrolled in online courses to enhance their capacity to teach remotely. Some respondents emphasized the preferred technology aspects to keep students grouped, engaged, and focused; 
and this could be possible with the use of Padlet, Kahoot, Wakelet, and Linoit, in addition to YouTube videos. Respondents agreed that "the transition was not just from teaching mode to another; the transition was from traditional instruction design to creative instructors and instructions."

\subsubsection{Online Assessment}

Content analysis proved the quality of the assessment that was implemented. As stated by the interviewees, higher education gave considerable attention to assessment to ensure the quality of learning and achieving the course and the program learning outcomes and adhere to the criteria of the accreditation authorities in the UAE. Based on the respondents, most assessment's title remains the same. However, the implementation and techniques differed distinctly. During the transition, assessments such as quizzes, exams were conducted physically on a hard copy and required direct proctoring, and some assignments were to be submitted on the students' portal. After the transition, "quizzes and exams still conducted. Yet, the difference underlies the implementation techniques", and all assessments were conducted online. As there are many assessment forms, each institution decided which assessment type need to be implemented based on the validity of the assessment and its relevance to the course level and nature, theoretical or practical course. The assessment models were carefully selected based on the feedback received from the instructors and being discussed and evaluated by the exam committees in each institution to ensure validity and relevance. A matrix of the range of possible assessment and questioning techniques was available for the faculty to assign and a map to course level and nature of the subject material could further serve as a benchmarking tool. Besides, the guidelines described the different types of assessment characteristics and assign a final assessment checklist for assessment moderation purposes.

Data revealed that multiple online assessment methods were embraced, including but not limited to quizzes, written assignments, exams, group projects and presentations, case studies, article reviews, and any appropriate assessment. The questions varied among assignments to include selected responses, essays, short essays, and critical thinking and problem-solving questions. Each category has its pros and cons in measuring various learning outcomes. For instance, a selected response, or a sequence of multiple-choice questions, allows learners to assess areas of knowledge proficiency but limited reasoning skills. Essays refer to answering essay questions or writing an entire essay; it enables creative and subjective responses but limited output and requires careful writing and analysis skills. Multiple types of assessment formats were implemented; ClosedBook Exam, Open-Book Exam, Project-Based Assessment linked with presentation to identify the verbal communication skills. As it was revealed, each university formed Exam Committee to facilitate the examination process. The exam committee was accountable for the moderation of the final assessment checklist, aiming to moderate the assessments to ensure the fairness, validity, and reliability of the assessment. Moderation is especially needed upon transitioning to online modes of delivery and administration of exams. For the online examination process and proctoring, both federal and private institutions used "Respond us techniques" connected with the lockdown browser. However, 
recently, some federal universities conducted the final examination process on campus following face-to-face examination guidelines and ensuring safety measures.

\subsection{Quantitative Data Analysis}

All issues related to outliers, missing values, and normality have been addressed prior to the analysis. To answer RQ 1 and 2 about students 'academic success and perception of the transition, students showed positive perception represented by the results of the three domains that measure students' perception. For perceived satisfaction $(M=5.394, S D=1.0478)$, for perceived usefulness $(M=5.277, S D=1.194)$, and for perceived e-learning effectiveness $(M=$ 4.999, $S D=1.313$ ). For the change in students' academic success as a result of the transition, it was revealed from the descriptive analysis that higher education students maintained the same level of success based on the grade scale in the UAE, CGPA1 $(M=3.358$, Median $=3.40$, Mode $=4.00$ and $S D=1.2318)$. For CGPA $2(M=3.376$, Median $=3.50$, Mode $=4.00$ and $S D=.6332)$, Cohen's $d$ was performed to support the findings, $d=.0182$, indicating no change in students' CGPA. To answer RQ 3 and discover whether students' perception of the transition is associated with their academic success (CGPA 2_post the transition), Correlation Coefficient analysis demonstrated a positive medium correlation between students' perception and their CGPA 2 (See Table 5 \& Figure 2).Simple Linear Regression was performed to predict the explanation of students' success through their perception of the transition to online learning. Data analysis discovered that $R^{2}=32.1 \%$ of the total variance in students' academic success (GPA) is accounted for their perception of the transition, $F(1,596)=281.789, p<.001$ is statistically significant, demonstrating a linear association between students' success and their perception of the transition. The following equation symbolizes the regression model.

Grade Point Average $=1.952+.398^{*}$ Students' Perception

Therefore, students' success increased by 0.4 units for each 1 unit in their perception of the transition (See figure 1).

Table 5: Pearson correlation between GPA 2 and transition to online learning

\begin{tabular}{|l|l|l|l|}
\hline \multicolumn{2}{|c|}{} & $\begin{array}{l}\text { Trans_Perception } \\
\text { Total }\end{array}$ & CGPA 2_Post \\
\hline \multirow{3}{*}{ Trans_Perception_Total } & Pearson Correlation & 1 & $.567^{* *}$ \\
\cline { 2 - 4 } & Sig. (2-tailed) & & .000 \\
\cline { 2 - 4 } & $\mathrm{N}$ & 598 & 598 \\
\hline
\end{tabular}




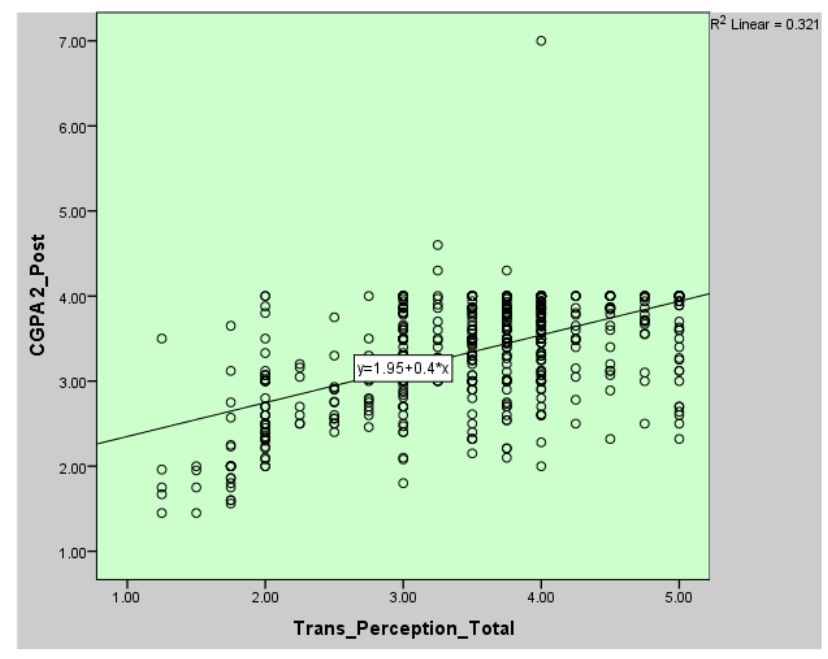

Figure 2: The Correlation between students' perception and their CGPA 2

\section{Discussion}

This research report discussed issues related to higher education teaching and learning and the post transition to online learning. Findings related to teaching approaches revealed that instructors were not prepared for the sudden transition. Nevertheless, their institutions' continuous professional developments helped them cope with the transition and adapt appropriately to online teaching. These findings are supported by McMinn et al. (2020), who explained that higher education in the UAE embraces effective teaching pedagogies, which could be interpreted in the context of commitment. Higher education adheres to the quality assurance criteria. In addition, findings on the lack of preparation agreed with Coman et al. (2020), who revealed that Romanian professors are not prepared appropriately for the transition. Furthermore, the study of Nathan (2020) discovered some challenges that hinder online learning effectiveness. These results are expected because the transition was unexpected and took place in no time. The rapid adaptation, because of the continuously offered professional development workshops, indicated that higher education promotes professors' capacities. These findings can be implemented in higher education when offering faculty orientation, and emphasis should be given to faculty preparedness to ensure the continuous improvement of professors' competencies. The discoveries of the assessment strategies revealed that higher education adopts appropriate assessment tools that are related to the course nature, level, and the course learning outcomes, which demonstrates the quality of teaching and assessment in the UAE higher education sector, which can be implemented through students' recruitment to increase the enrolment.

The finding of student academic success is expected as it was revealed by Moussa and Ali (2021) that students in higher education institutions in the UAE show medium to high academic success as it was considered by CGPA. Furthermore, the outcomes of the stability of students CGPA after the transition could be interpreted as the dedicated work of students and their resilience to cope with the transition to online learning and their technical skills that enable 
them to succeed. Thus, these results were supported by the positive perception about the transition and the effectiveness of e-learning among students. Thus, higher education appears to embrace a robust e-system to ensure the learning quality, which sheds the light on the efforts done to enhance the higher education system in the UAE. The positive correlation and the regression model of students' perception and their CGPA are anticipated; those students who perceived the transition as a new learning experience and adapted rapidly have maintained the same academic achievement. Moreover, the positive perception shows the efforts made to facilitate the transition. The students' positive perception supported the findings of Nathan (2020) who found that higher education leaders in the UAE perceive the transition positively. These findings could be implemented in the college counseling centers to enhance students' perceptions of sudden transition and to ensure their ability and resilience to cope with unexpected challenges. The limitations of this research study underlined the correlation design because it does not reflect direct causation but just an association between variables.

\section{Conclusion}

This paper analyzed the higher education teaching, assessment, and students' achievement after the transition to online learning. Above and beyond, the study explored the relationship between students' perception of the transition to online learning and academic success. The findings demonstrated the professors' lack of readiness. In addition, higher education institutions adapted appropriately and adjusted their teaching styles and assessment techniques by considering course nature and level to match the online learning demands. Moreover, students showed a positive perception of the transition and were identified with outstanding academic success with a medium positive correlation between these two variables. Moreover, those students who perceived the transition as a new learning experience successfully maintained a stable academic achievement.

\section{Recommendations}

The findings of this research paper can be implemented by embracing a blended learning platform throughout academic programs to allow students gain experience of the blended learning environment. Furthermore, students' forums, study groups, and social engagement can be offered as an alternative way of the physical activities. Nonetheless, students' orientation can include training sessions to help students adapt and cope with challenges to ensure their wellbeing for better academic success. Future research should focus on discovering the factors that support students' academic achievement stability from face-toface to online learning. Moreover, future work can examine students' acceptance to continue online learning as an alternative learning mode.

\section{References}

Al-Naqbi, A. K., \& Alshannag, Q. (2018). The status of education for sustainable development and sustainability knowledge, attitudes, and behaviors of UAE University students. International Journal of Sustainability in Higher Education, 19(3), 566-588. http:/ / doi.org/10.1108/IJSHE-06-2017-0091 
Al-Qirim, N. (2016). Smart board technology success in tertiary institutions: The case of the UAE University. Education and Information Technologies, 21(2), 265-281. http://doi.org/10.1007/s10639-014-9319-7

Cachia, M., Lynam, S., \& Stock, R. (2018). Academic success: Is it just about the grades? Higher Education Pedagogies, 3(1), 434-439. https:// doi.org/10.1080/23752696.2018.1462096

Canales, A., \& Maldonado, L. (2018). Teacher quality and student achievement in Chile: Linking teachers' contribution and observable characteristics. International Journal of Educational Development, 60, 33-50.

Carolan, C., Davies, C. L., Crookes, P., McGhee, S., \& Rox-Burgh, M. (2020). COVID 19: Disruptive impacts and transformative opportunities in undergraduate nurse education. Nurse Education Practice, 46. http://doi.org/10.1016/j.nepr.2020.102807

Chaturvedi, S., Purohit, S., \& Verma, M. (2021). Effective teaching practices for success during COVID 19 pandemic: Towards phygital learning. Frontiers in Education. 6. https://doi.org/10.3389/feduc.2021.646557

Coman, C., Țîru, L. G., Meseșan-Schmitz, L., Stanciu, C., \& Bularca, M. C. (2020). Online teaching and learning in higher education during the coronavirus pandemic: Students' perspective. Sustainability, 12(24), 10367.

Daniels, L. M., Goegan, L. D., \& Parker, P. C. (2021). The impact of COVID-19 triggered changes to instruction and assessment on university students' self-reported motivation, engagement, and perceptions. Social Psychology of Education, 24(1), 299-318. https://doi.org/10.1007/s11218-021-09612-3

Dubai Knowledge. (2017). Higher education in Dubai. Guidelines for advertising and marketing.

https://www.khda.gov.ae/Areas/Administration/Content/FileUploads/Publi cation/Documents/English/20170523085007_Dubai_Higher_Education_Guide. pdf

Dwivedi, Y., Hughes, L., Coombs, C., Constantiou, I., Duan, Y., Edwards, J., ... Upadhyay, N. (2020). Impact of COVID-19 pandemic on information management research and practice: Transforming education, work, and life. International Journal of Information Management, 55. http://doi.org/10.1016/j.ijinfomgt.2020.102211

George, M. L. (2020). Effective teaching and examination strategies for undergraduate learning during COVID-19 school restrictions. Journal of Educational Technology System, 49(1), 23-48. http://doi.org/10.1177/0047239520934017

Hepworth, D., Littlepage, B., \& Hancock, K. (2018). Factors influencing university student academic success. Educational Research Quarterly, 42(1), 45-61.

Jackson, L. (2015). Challenges to the global concept of student-centered learning with special reference to the United Arab Emirates: 'Never fail a Nahayan', Educational Philosophy and Theory, 47(8), 760-773. https://doi.org/10.1080/00131857.2014.901161

Jaquette, O., \& Curs, B. R. (2015). Creating the out-of-state university: Do public universities increase nonresident freshman enrollment in response to declining state appropriations? Research in Higher Education, 56(6), 535-565.

Liaw, S. S. (2008). Investigating students' perceived satisfaction, behavioral intention, and effectiveness of e-learning: A case study of the blackboard system. Computers $\mathcal{E}$ education, 51(2), 864-873.

McMinn, M., Dickson, M., \& Areepattamannil, S. (2020). Reported pedagogical practices of faculty in higher education in the UAE. Higher Education (2020). https:// doi.org/10.1007/s10734-020-00663-7 
Mihaela, P. (2015). Psychological factors of academic success. Procedia - Social and Behavioral Sciences, 180, 1632-1637.

Ministry of Education. (2019). Ministry of education launches national higher education strategy.

https://www.moe.gov.ae/En/MediaCenter/News/Pages/higherstra17.aspx

Mishra, L., Gupta, T., \& Shree, A. (2020). Online teaching-learning in higher education during lockdown period of COVID-19 pandemic. International Journal of Educational Research Open. http://doi.org/10.1016/j.ijedro.2020.100012

Moussa, N. M., \& Ali, W. F. (2021). Exploring the relationship between students' academic success and happiness levels in the higher education settings during the lockdown period of COVID-19. Psychological Reports, https:// doi.org/10.1177/0033294121994568

Nathan, S. (2020). Where does higher education go from here? https://www.alfanarmedia.org/2020/05/future-higher-education-go-from-here/

O'Brien, M., \& Blue, L. (2018). Towards a positive pedagogy: Designing pedagogical practices that facilitate positivity within the classroom. Educational Action Research, 26(3), 365-384.

Park, E. L., \& Choi, B. K. (2014). Transformation of classroom spaces: Traditional versus active learning classroom in colleges. Higher Education, 68(5), 749-771.

Pozo Sanchez, S., Lopez Belmonte, J., Moreno Guerrero, A. J., \& Lopez Nunez, J. A. (2019). Impact of educational stage in the application of flipped learning: A contrasting analysis with traditional teaching. Sustainability, 11(21), 5968. https:// doi.org/10.3390/su11215968

Sandri, O. (2020). What do we mean by 'pedagogy' in sustainability education? Teaching in Higher Education, 1-16.

Toquero, C. M. (2020). Challenges and opportunities for higher education amid the COVID-19 pandemic: The Philippine context. Pedagogical Research, 5(4). https://doi.org/10.29333/pr/7947

UAE Vision 2021. (2010). UAE vision 2021 report. https://www.vision2021.ae/en/uaevision

White, P. (2015). What makes a successful undergraduate? The relationship between student characteristics, degree subject and academic success at a university. British Educational Research Journal, 41(4), 686-708. https://doi.org/10.1002/berg.3158

Yang, H., \& Ma, J. (2020). How an epidemic outbreak impacts happiness: Factors that worsen (vs. protect) emotional well-being during the Coronavirus Pandemic. Psychiatry Research, 289. https:// doi.org/10.1016/j.psychres.2020.113045

York, T., Gibson, C., \& Rankin, S. (2015). Defining and measuring academic success. Practical Assessment and Research Evaluation, 5(20), 1-10. 